\title{
Analysis and Investigation of a Novel Microwave Sensor with High Q-Factor for Oil Sensing
}

\author{
Ammar Alhegazi ${ }^{1}$, Zahriladha Zakaria ${ }^{2}$, Noor Azwan Shairi ${ }^{3}$, Tole Sutikno ${ }^{4}$, Rammah A. Alahnomi ${ }^{5}$, \\ Ahmed Ismail Abu-Khadrah ${ }^{6}$ \\ 1,2,3,5 Microwave Research Group (MRG), Centre for Telecommunication Research \& Innovation (CeTRI), \\ Fakulti Kejuruteraan Elektronik dan Kejuruteraan Komputer (FKEKK), Universiti Teknikal Malaysia Melaka (UTeM), \\ Hang Tuah Jaya, 76100, Durian Tunggal, Melaka, Malaysia \\ ${ }^{4}$ Department of Electrical Engineering, Universitas Ahmad Dahlan, Yogyakarta, Indonesia \\ ${ }^{6}$ Computer Engineering Department, Faculty of Engineering, AMA International University Bahrain, 8041, \\ Salmabad, Kingdom of Bahrain
}

\begin{tabular}{|c|c|}
\hline Article Info & ABSTRACT \\
\hline Article history: & \multirow{10}{*}{$\begin{array}{l}\text { In this paper, a novel microwave sensor with high Q-factor for oil sensing is } \\
\text { analyzed and investigated. The new design is based on a gap waveguide } \\
\text { cavity resonator (GWCR). To characterize and evaluate the sample, the oil } \\
\text { under tested (OUT) is injected into a Teflon tube, which is passing through } \\
\text { the microfluidic channel that is located in the middle of the cavity where the } \\
\text { electric field concentrates. The results show that the proposed sensor has a } \\
\text { high Q-factor of } 4832 \text {. Moreover, the proposed design has the ability to sense } \\
\text { and detect different types of oils with a small variation of permittivities such } \\
\text { as Fish oil, Coconut oil, Olive oil, Linseed oil and Castor oil. The } \\
\text { permittivity equation is extracted using the polynomial fitting method to } \\
\text { define unknown dielectric properties of the OUT. The results show that the } \\
\text { evaluated permittivity using the proposed sensor has a good agreement with } \\
\text { the ideal permittivity. Therefore, the proposed sensor is a good candidate for } \\
\text { oil processing in food industries. }\end{array}$} \\
\hline Received Oct 1, 2018 & \\
\hline Revised Nov 24, 2018 & \\
\hline Accepted Nov 30, 2018 & \\
\hline Keywords: & \\
\hline Dielectric Properties & \\
\hline Gap Waveguide & \\
\hline Liquid Detection & \\
\hline Microwave Sensor & \\
\hline Oil Sensing & \\
\hline
\end{tabular}

Copyright ()$^{\circ} 2018$ Institute of Advanced Engineering and Science. All rights reserved.

\section{Corresponding Author:}

Zahriladha Zakaria,

Fakulti Kejuruteraan Elektronik dan Kejuruteraan Komputer (FKEKK),

Universiti Teknikal Malaysia Melaka (UTeM),

Hang Tuah Jaya, 76100, Durian Tunggal, Melaka, Malaysia.

Email: zahriladha@utem.edu.my

\section{INTRODUCTION}

Material sensing is very important for industries to control the quality and safety of the products. In food products, the concentration of some ingredients may influence the consumers and cause some diseases such as allergic, poison and sometimes it may cause cancer. Therefore, it is important to characterize the materials and identify the ingredients before selling the product to the consumers. Each material has a specific electric behaviour depends on the dielectric properties, thus material properties measurement plays an important role in increasing the demand number of industrial applications such as quality control in food industries and bio-sensing [1-2].

In the recent years, many methods of microwave sensor have been used for material properties measurement [3-4]. Different microwave sensors have been used in different applications such as planar split ring resonator for liquid [5] and solid [6-8] detection. Vertically staked ring resonator has been used for Petroleum Oils sensing [9-10]. Another method by using a substrate integrated waveguide for liquid [11] and humidity [12] detection. These sensors attract research interest due to their advantages such as simplicity and low cost. However, these techniques showed low Q-factors, which may increase the error percentages and leads to inaccurate characterization of the material. 
Microwave sensors depend on the frequency and quality factor of the resonator. Therefore, in this work the gap waveguide is chosen due to its high concentration of the electric field, which provides high Qfactor. Gap waveguide (GW) technique has gained research interest where it has been used for antenna design [13] and filter design [14]. However, for the first time, GW is used for material sensing in this article.

In this paper, a novel microwave sensor with high Q-factor for oil sensing is presented. The proposed sensor is designed based on gap waveguide cavity resonator (GWCR). The new geometry provides a high electric field in the cavity region, which leads to providing high Q-factor and high sensitivity. This technique is based on perturbation theory, where the oil under test (OUT) is placed in the maximum electric field region using a Teflon tube. The OUT complex permittivity is identified using the polynomial fitting method. Results from this study show that the evaluated permittivity using the proposed sensor has a good agreement with the ideal permittivity.

\section{SENSOR DESIGN}

The Q-factor is significant for microwave sensors. It shows how much the sensor is sensitive and accurate. It quantifies the amount of electric field concentration and the dissipated energy in the sensor. The loaded Q-factor (QL) can be calculated by using [15]:

$$
\frac{1}{Q_{L}}=\frac{1}{Q_{U}}+\frac{1}{Q_{E}}
$$

Where QU and QE are the unloaded and external quality factors respectively. Qu is related to the loss of the sensor itself, and QE is related to the loss caused by the OUT which is calculated by using [16]:

$$
Q_{E}=10^{-[S 21(d B) / 20]} Q_{L}
$$

Therefore, the unloaded Q-factor can be calculated using [17]:

$$
Q_{U}=\frac{Q_{L}}{1-S 21}
$$

Thus, to measure the Q-factor with the OUT, the following equation is used [18]:

$$
Q_{L}=\frac{f_{o}}{B W}
$$

Where $f_{o}$ the resonant frequency and $\mathrm{BW}$ is the $3 \mathrm{~dB}$ bandwidth. To calculated the Q-factor without the OUT, the following equation is used [19]:

$$
Q_{L}=\frac{2 f_{o}}{B W}
$$

The optimum values of the proposed designed are obtained at $6.1 \mathrm{GHz}$ as illustrated in Table 1 . The proposed GWCR is constructed of upper and lower aluminium plates fed by two SMA connectors as shown in Figure 1. The lower plate consists of cavity, microfluidic channel and square array pins with size of $1 \mathrm{~mm} 2$ and height less than $\lambda / 4$. The upper metal plate consists of cavity and microfluidic channel, the SMA connectors are connected to the upper plate as well as shown in Figure 1. The upper plate is placed at $1 \mathrm{~mm}$ from the top of the pins surface. The two rows of array pins on each side of the ground plate provide a high electric field and increase the interaction with the OUT as shown in Figure 2. The interaction between the electric field and the OUT is linear, thus the change in relative permittivity of the OUT leads to change in the resonant frequency. 
Table 1. The optimum values of the design parameters

\begin{tabular}{cccc}
\hline Parameter & Value $(\mathrm{mm})$ & Parameter & Value $(\mathrm{mm})$ \\
\hline$W$ & 38.20 & $d_{2}$ & 18.00 \\
$L$ & 35.40 & $x$ & 5.10 \\
$d$ & 1.00 & $s$ & 1.60 \\
$d_{l}$ & 1.50 & $p$ & 1.80 \\
$y$ & 6.35 & $t$ & 5.00 \\
$h$ & 15.75 & $h_{1}$ & 21.70 \\
\hline
\end{tabular}

The operation principles of the GWCR is based on the gap waveguide technology proposed in [20], where the upper plate acts as a perfect electric conductor, while the lower plate acts as a perfect magnetic conductor. Moreover, the square array pins in the lower plate restrict the propagation of the waves from all directions and this leads to increase the electric field in the pins area as shown in Figure 2. A Teflon tube with permittivity of 2.1 is inserted through the microfluidic channel to evaluate the OUT as shown in Figure 2.

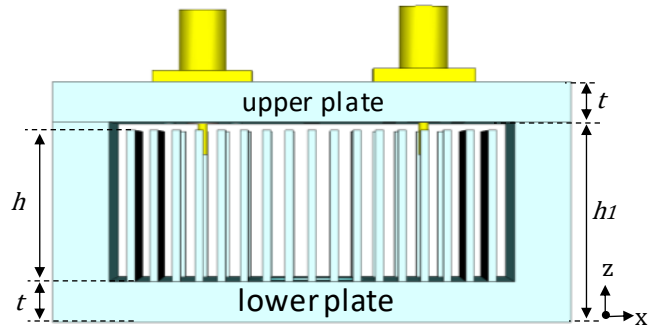

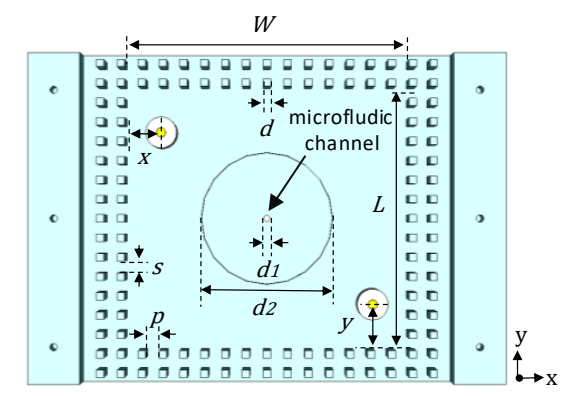

Lower plate

Figure 1. Simulated structure of the proposed sensor using GWCR
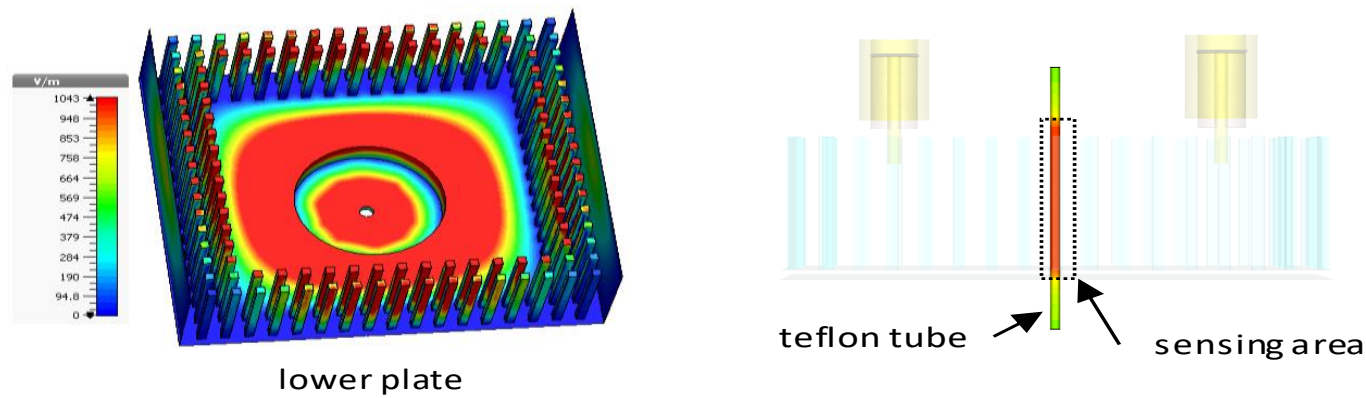

Figure 2. Simulated electric field (v/m) of the proposed sensor at $6.1 \mathrm{GHz}$

\section{RESULTS AND ANALYSIS}

A parametric study is carried out for varied lengths of the of pins as shown in Figure 3. It can be seen that the change in the length of the pins leads to change in the resonant frequency where the length of the pins increases, the resonant frequency decreases.

The proposed sensor shows its ability to sense and detect different types of oils such as Fish oil, Coconut oil, Olive oil, Linseed oil and Castor oil, with relative permittivity of 2.6, 2.9, 3.1, 3.5, 4.7 respectively as shown in Figure 4. It can be observed that the relationship between the resonant frequency and the permittivity is inversely proportional to each other, where the resonant frequency is decreasing by increasing the permittivity, thus when the permittivity is 2.6 the resonant frequency appears at $6.0876 \mathrm{GHz}$, while when the permittivity is 4.7 the resonant appears at $6.0814 \mathrm{GHz}$. 


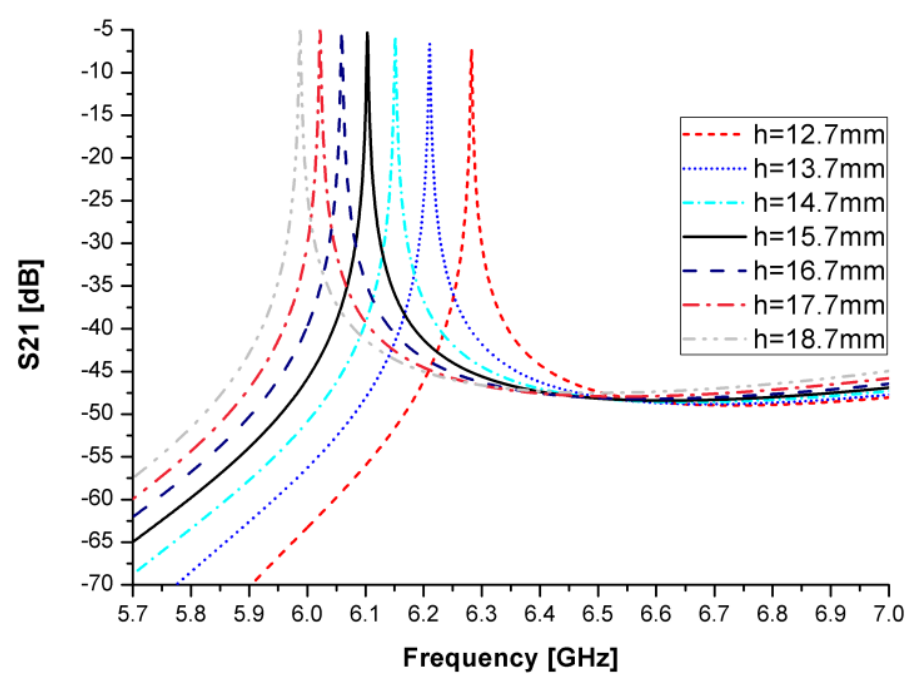

Figure 3. Transmission coefficient of the proposed sensor for varied lengths of the pins

The polynomial graph of the proposed sensor is plotted according to the resonant frequency shifting and permittivity as shown in Figure 5. From the polynomial graph, the permittivity equation is extracted as follow:

$$
\varepsilon^{\prime}=330.59 f^{2}-4364.7 f+14322
$$

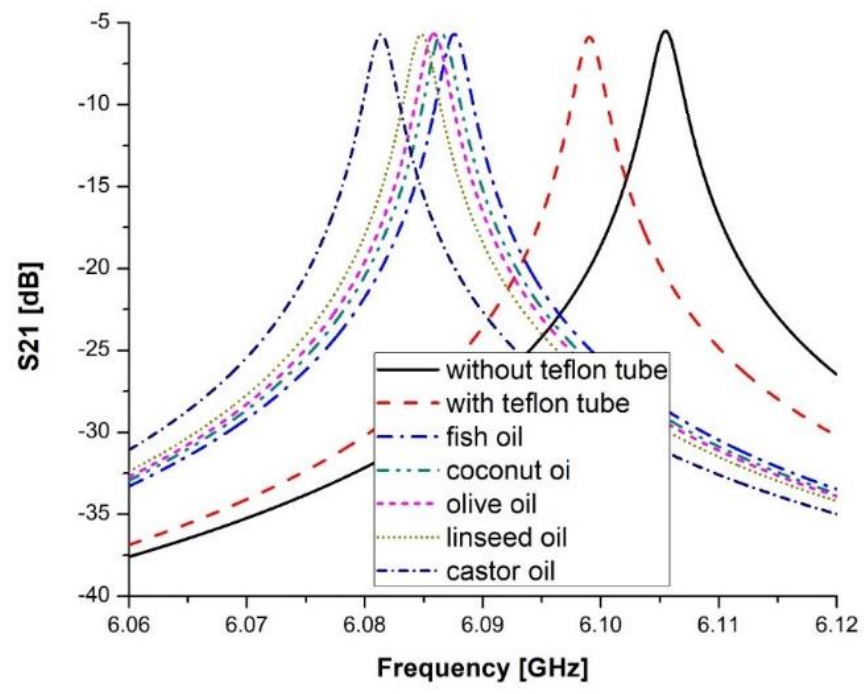

Figure 4. Transmission coefficient of the proposed sensor with and without OUT 


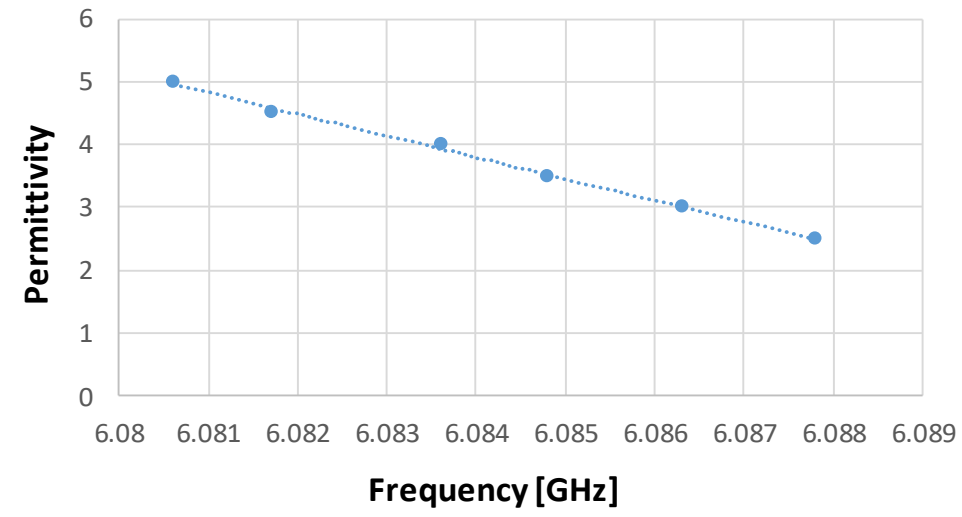

Figure 5. Polynomial graph of the proposed sensor

To validate the accuracy of the proposed sensor, the permittivity of the OUT is evaluated using the proposed sensor and compared with the ideal permittivity, as shown in Table 2.

Table 2. Comparison between the evaluated permittivity by the proposed sensor and the ideal permittivity

\begin{tabular}{cccc}
\hline OUT & Frequency $(\mathrm{GHz})$ & Ideal Permittivity $\left(\varepsilon^{\prime}\right)$ & Proposed sensor $\left(\varepsilon^{\prime}\right)$ \\
\hline Fish oil & 6.0876 & 2.6 & 2.745 \\
Coconut oil & 6.0865 & 2.9 & 3.11 \\
Olive oil & 6.0858 & 3.1 & 3.357 \\
Linseed oil & 6.0848 & 3.5 & 3.699 \\
Castor oil & 6.0814 & 4.7 & 4.864 \\
\hline
\end{tabular}

From Table 2 it can be said that a good agreement between the proposed sensor and the ideal permittivity, which means that the proposed sensor is accurate and has the ability to detect different types of oils. However, very small change of the permittivity between the proposed sensor and the ideal permittivity mainly due to the difference between the simulation environment and practical environment.

From the previous results, it can be said that the proposed sensor is reliable to be used for oil sensing in food industries. The results show that the proposed sensor has the highest Q-factor compared to the recently proposed sensors as shown in Table 3.

Table 3. Comparison between the proposed sensor and recently reported researches

\begin{tabular}{ccc}
\hline Reference & Technique & $\mathrm{Q}_{\mathrm{u}}$-Factor \\
\hline$[5]$ & Planar double split ring resonator & 525 \\
{$[6]$} & Complementary split ring resonator & 80 \\
{$[7]$} & Planar symmetrical split ring resonator & 652 \\
{$[11]$} & Substrate Integrated waveguide & 334.6 \\
{$[10]$} & Vertically staked ring resonator & 146.67 \\
{$[12]$} & Cavity Substrate Integrated Waveguides & $\approx 300$ \\
{$[21]$} & Re-Entrant cavity & 1190 \\
{$[22]$} & Complementary folded arm split ring resonator & 506 \\
{$[23]$} & Multiple split ring resonator & 430 \\
Proposed sensor & Gap waveguide cavity resonator & 4832 \\
\hline
\end{tabular}

\section{CONCLUSION}

In this paper, a novel microwave sensor with high Q-factor for oil sensing is analyzed and investigated. This technique is based on gap waveguide cavity resonator (GWCR). The results show that the GWCR has the ability to detect different types of oils with a small variation of permittivities such as Fish oil, Coconut oil, Olive oil, Linseed oil and Castor oil. The GWCR is designed and analyzed using Computer Simulation Technology (CST). The electric field of the GWCR is investigated, where the results show that the electric field more concentrates in the cavity, thus the OUT is placed in the cavity using Teflon tube. The results from this study show that the proposed sensor is a good candidate to be used for oil sensing in food industries. 


\section{ACKNOWLEDGEMENTS}

This work was supported by UTeM Zamalah Scheme. The authors would also like to thank Centre for Research and Innovation Management (CRIM), Centre of Excellence, UTeM, UTeM's research grant JURNAL/2018/FKEKK/Q00001 and Universiti Teknikal Malaysia Melaka (UTeM) for their encouragement and help in sponsoring this study.

\section{REFERENCES}

[1] S. N. Jha, K. Narsaiah, a. L. Basediya, R. Sharma, P. Jaiswal, R. Kumar, and R. Bhardwaj, "Measurement techniques and application of electrical properties for nondestructive quality evaluation of foods-a review," J. Food Sci. Technol., vol. 48, no. 4, pp. 387-411, 2011.

[2] N. A. Rahman, Z. Zakaria, R. A. Rahim, and D. Yosza, "Characterization: A review Planar Microwave Sensors for Accurate Measurement of Material Characterization: A Review," TELKOMNIKA, vol. 15, no. September, pp. 1108-1118, 2017.

[3] A. Azuan, M. Bahar, Z. Zakaria, A. A. Isa, E. Ruslan, and R. A. Alahnomi, "A Review of Characterization Techniques for Materials ' Properties Measurement Using Microwave Resonant Sensor," J. Telecommun. Electron. Comput. Eng., vol. 7, no. 2, pp. 1-6, 2015.

[4] "Planar Microwave Sensors for Accurate Measurement of Material Characterization : A Review Refbacks," vol. 62, no. 274, p. 564604, 2017.

[5] A. A. M. Bahar, Z. Zakaria, S. R. A. Rashid, A. A. M. Isa, R. A. Alahnomi, and D. Tunggal, "Dielectric analysis of liquid solvents using microwave resonator sensor for high efficiency measurement," Microw. Opt. Technol. Lett., vol. 59, no. 2, pp. 367-371, 2017.

[6] M. A. H. Ansari, A. K. Jha, and M. J. Akhtar, "Design and Application of the CSRR-Based Planar Sensor for Noninvasive Measurement of Complex Permittivity,” IEEE Sens. J., vol. 15, no. 12, pp. 7181-7189, 2015.

[7] R. A. Alahnomi, Z. Zakaria, E. Ruslan, S. R. Ab Rashid, and A. A. Mohd Bahar, "High-Q sensor based on symmetrical split ring resonator with spurlines for solids material detection," IEEE Sens. J., vol. 17, no. 9, pp. 2766$2775,2017$.

[8] R. Alahnomi, N. Binti, A. Hamid, Z. Zakaria, T. Sutikno, and A. Azuan, "Microwave Planar Sensor for Permittivity Determination of Dielectric Materials," Indones. J. Electr. Eng. Comput. Sci., vol. 11, no. 1, pp. 362-371, 2018.

[9] A. A. Mohd Bahar, Z. Zakaria, A. A. Md Isa, Y. Dasril, and R. A. Alahnomi, "The CSIW Resonator Sensor for Microfluidic Characterization Using Defected Ground Structure," J. Telecommun. Electron. Comput. Eng., vol. 10, no. 2-6, pp. 35-40, 2018.

[10] S. Kulkarni and M. S. Joshi, "Design and Analysis of Shielded Vertically Stacked Ring Resonator as Complex Permittivity Sensor for Petroleum Oils," vol. 63, no. 8, pp. 2411-2417, 2015.

[11] C. Liu and F. Tong, "An SIW Resonator Sensor for Liquid Permittivity Measurements at C Band," IEEE Microw. Wirel. Components Lett., vol. 25, no. 11, pp. 751-753, 2015.

[12] H. El Matbouly, N. Boubekeur, and F. Domingue, "Passive Microwave Substrate Integrated Cavity Resonator for Humidity Sensing," IEEE Trans. Microw. Theory Tech., vol. 63, no. 12, pp. 4150-4156, 2015.

[13] A. U. Zaman and P.-S. Kildal, "Slot antenna in ridge gap waveguide technology," 2012 6th Eur. Conf. Antennas Propag., no. March, pp. 3243-3244, 2012.

[14] A. K. Horestani and M. Shahabadi, "Balanced Filter with Wideband Common-Mode Suppression in Groove Gap Waveguide Technology," IEEE Microw. Wirel. Components Lett., vol. 28, no. 2, pp. 132-134, 2018.

[15] E. Pucci, A. U. Zaman, E. Rajo-iglesias, P. Kildal, and A. Kishk, "Study of Q -factors of ridge and groove gap waveguide resonators," IET Microwaves, Antennas Propag., vol. 7, no. May, pp. 900-908, 2013.

[16] J. Papapolymerou, J. Cheng, J. East, and L. P. B. Katehi, "A Micromachined High- X-Band Resonator," IEEE Microw. Guid. Wave Lett., vol. 7, no. 6, pp. 168-170, 1997.

[17] Darko Kajfez, "Q-Factor," in Encyclopedia of RF and Microwave Engineering, K. Chang, Ed. Wiley Online Library, 2005.

[18] David M. Pozar, “Microwave Engineering,” book, Univ. Massachusetts Amherst, vol. 1, pp. 144-146, 2011.

[19] A. Alhegazi, Z. Zakaria, R. A. Alahnomi, E. Ruslan, and S. R. A. Rashid, "Design of Double Ring Resonator ( DRR ) for Material Properties Measurement," in IEEE International Conference on Intelligent \& Advanced Systems, 2016, pp. 1-6.

[20] P. S. Kildal, E. Alfonso, A. Valero-Nogueira, and E. Rajo-Iglesias, "Local metamaterial-based waveguides in gaps between parallel metal plates," IEEE Antennas Wirel. Propag. Lett., vol. 8, pp. 84-87, 2009.

[21] H. Hamzah, A. Abduljabar, J. Lees, and A. Porch, "A Compact Microwave Microfluidic Sensor Using a Re-Entrant Cavity," Sensors, vol. 18, no. 3, p. 910, 2018.

[22] N. A. Rahman, Z. Zakaria, R. A. Rahim, Y. Dasril, A. Azuan, and M. Bahar, "Dual Band Planar Microwave Sensor for Dielectric Characterization using Solid and Liquid Sample," J. Telecommun. Electron. Comput. Eng., vol. 10, no. 2, pp. 27-32, 2018.

[23] A. A. Mohd Bahar, Z. Zakaria, A. A. Md Isa, Y. Dasril, S. R. Ab Rashid, and R. a. Alahnomi, "The dielectric constant analysis for aqueous characterization using split ring resonator sensor," J. Telecommun. Electron. Comput. Eng., vol. 9, no. 2-13, pp. 75-80, 2017. 